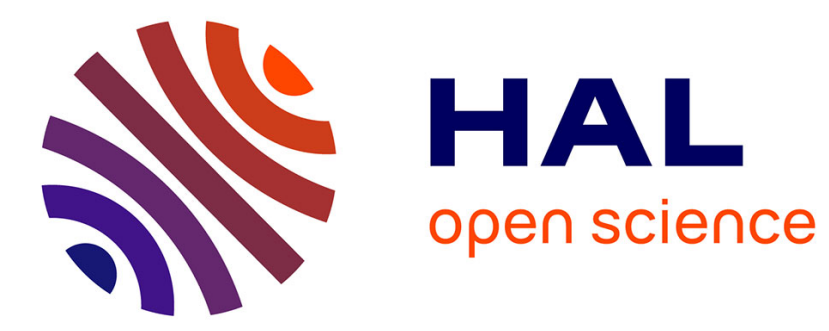

\title{
FRACTURE IN ROCKET PROPELLANT
}

\author{
L. Seaman, D. Erlich
}

\section{To cite this version:}

L. Seaman, D. Erlich. FRACTURE IN ROCKET PROPELLANT. Journal de Physique IV Proceedings, 1991, 01 (C3), pp.C3-557-C3-564. 10.1051/jp4:1991378 . jpa-00250523

\section{HAL Id: jpa-00250523 https://hal.science/jpa-00250523}

Submitted on 1 Jan 1991

HAL is a multi-disciplinary open access archive for the deposit and dissemination of scientific research documents, whether they are published or not. The documents may come from teaching and research institutions in France or abroad, or from public or private research centers.
L'archive ouverte pluridisciplinaire HAL, est destinée au dépôt et à la diffusion de documents scientifiques de niveau recherche, publiés ou non, émanant des établissements d'enseignement et de recherche français ou étrangers, des laboratoires publics ou privés. 
Colloque C3, suppl. au Journal de Physique III, Vol. 1, octobre 1991

\title{
FRACTURE IN ROCKET PROPELLANT
}

\author{
L. SEAMAN and D.C. ERLICH
}

SRI International, 333 Ravenswood Avenue, Menlo Park, CA 94025, U.S.A.

Résumé: Dans le cadre d'un programme de sécurité , nous avons étudié la fissuration de différentes charges propulsives au moyen des tests par impact de plaque et de Taylor, examinant ainsi à la fois le chargement plan unidimensionnel et bidimensionnel axysymétrique. Nous exposons içi les résultats expérimentaux pour une poudre propulsive (désignée par Propellant $B$ ), nous décrivons le modèle constitutif développé et nous montrons comment nous en déduisons les paramètres de fragmentation de la poudre propulsive. La partie du déviateur des contraintes des relations constitutives est viscoélastique à cause de l'influence marquée de la vitesse sur le module de cisaillement et elle est viscoplastique pour représenter la variation de la limite élastique avec la vitesse de déformation. Les fractures semblent dûes aux déformations en tension; les déformations en cisaillement paraissent ne causer aucun dommage.

\begin{abstract}
As part of a safety program, we studied the fracture of several rocket propellants under plate impacts and Taylor tests, thus examining fracture under both one- dimensional planar and two-dimensional axisymmetric loadings. Here we outline the experimental results for one propellant (termed Propellant B), describe the constitutive model developed, and show how we derived the fracture parameters for the propellant. The deviatoric stress portion of the constitutive relations is viscoelastic because of the marked rate dependence of the shear modulus and is viscoplastic to represent the variation of yield strength with strain rate. Fracture appears to be caused by tensile strains; shearing strains of 1 or more appeared to cause no damage.
\end{abstract}

\section{1.- Introduction.}

We performed gas-gun impact experiments and analyses to study the high-strain-rate behavior, particularly tensile fracture, of an energetic propellant called Propellant B. Previous work [1] had shown that a microfracture model containing nucleation, growth, and coalescence processes for cracks is effective in describing dynamic fracture, spall, and fragmentation in a propellant for which the model parameters have been experimentally derived. Those previous tests were all one-dimensional planar impacts conducted in 1 to $3 \mu \mathrm{s}$. Here we wished to study tensile damage and compressive response over a wider range of strain rates (millisecond to microsecond loadings) and stress states (one-dimensional planar and two-dimensional axial symmetry). We expected to find new rate effects and possibly shearing or other damage modes. We show, through micrographs of target cross sections, the nature of the cracking that occurs in this propellant under various stress states, and we develop a microfracture model to approximate the observed fracture damage.

\section{2.- Experimental observations.}

Two types of gas-gun impact experiments were performed. In the first, a thin flyer plate of PMMA was propelled at 60 to $130 \mathrm{~m} / \mathrm{s}$ at a $5.08-\mathrm{mm}$-thick target plate of the propellant. The impact conditions for these tests and the observed damage in the targets are listed in Table 1. In this test the material exhibits primarily one-dimensional flow, the crack plane is normal to the direction of propagation, and there is little shearing response. We have traditionally used this type of test to determine the microfracture nucleation and growth parameters. 
The damage in the disks ranged from none to a few cracks to heavily fragmented. Figure 1 shows a cross section from a plate impact test in which the spall zone is about $63 \%$ through the target thickness (impact at the top in the figure). The spall zone encompasses coalesced cracks scattered over an axial extent of approximately $0.5 \mathrm{~mm}$, or $10 \%$ of the specimen thickness. A higher magnification view of a small crack in another impacted specimen is shown in Figure 2 . The approximately $25-\mu \mathrm{m}$-diameter circular particles were identified as aluminum. The larger (up to about $100 \mu \mathrm{m}$ ), irregularly shaped particles are the various high explosive (HE) granules. The dominant failure mechanism appears to be separation of the HE granules from the matrix. There is little evidence of intergranular cracking in any of our studies. Fracture

Table 1 Plate Impact Fracture Test Parameters and Results

\begin{tabular}{|c|c|c|c|c|c|}
\hline $\begin{array}{l}\text { Test } \\
\text { No.a }\end{array}$ & $\begin{array}{l}\text { Impact } \\
\text { Velocity } \\
(\mathrm{m} / \mathrm{s})^{\mathrm{b}}\end{array}$ & $\begin{array}{c}\text { Peak } \\
\text { Stress } \\
\text { (MPa) }\end{array}$ & $\begin{array}{c}\text { Observ. } \\
\text { cracks } \\
\left.\text { (No. } / \mathrm{cm}^{3}\right) \\
\end{array}$ & $\begin{array}{c}\text { Damage } \\
T_{F}{ }^{\tau F} \gamma_{S}^{3} N_{J} R_{\perp}^{3}\end{array}$ & $\begin{array}{c}\text { Observed Tensile Fracture } \\
\text { Results }\end{array}$ \\
\hline $\begin{array}{r}17 \\
11 \\
9 \\
15 \\
14 \\
14 \\
10 \\
16\end{array}$ & $\begin{array}{r}62 \\
65 \\
86 \\
87 \\
96 \\
109 \\
129\end{array}$ & $\begin{array}{l}115 \\
120 \\
160 \\
160 \\
175 \\
200 \\
250\end{array}$ & $\begin{array}{r}9000 \\
800 \\
- \\
- \\
-\end{array}$ & $\begin{array}{l}\overline{0} \\
0.07 \\
0.135 \\
- \\
\overline{0} \\
>0.5 \\
1.0\end{array}$ & $\begin{array}{l}\text { Incipient crack formation } \\
\text { Incipient crack formation } \\
\text { Incipient crack formation } \\
\text { No damage } \\
\text { Significant crack coalescence } \\
\text { Partially spalled } \\
\text { Complete spall }\end{array}$ \\
\hline
\end{tabular}

Listed in order of projectile velocity. All targets were $5.08 \mathrm{~mm}$ thick.

b Impacting plates were Type II-UVA polymethyl methacrylate (PMMA), $2.79 \mathrm{~mm}$ thick.

c The peak compressive stress was computed from $P(G P a)=6.2 \mu+100 \mu^{2}$ (eq. 1, below).

- Maximum crack density in the sample, estimated from a surface-to-volume transformation of the observed cracks.

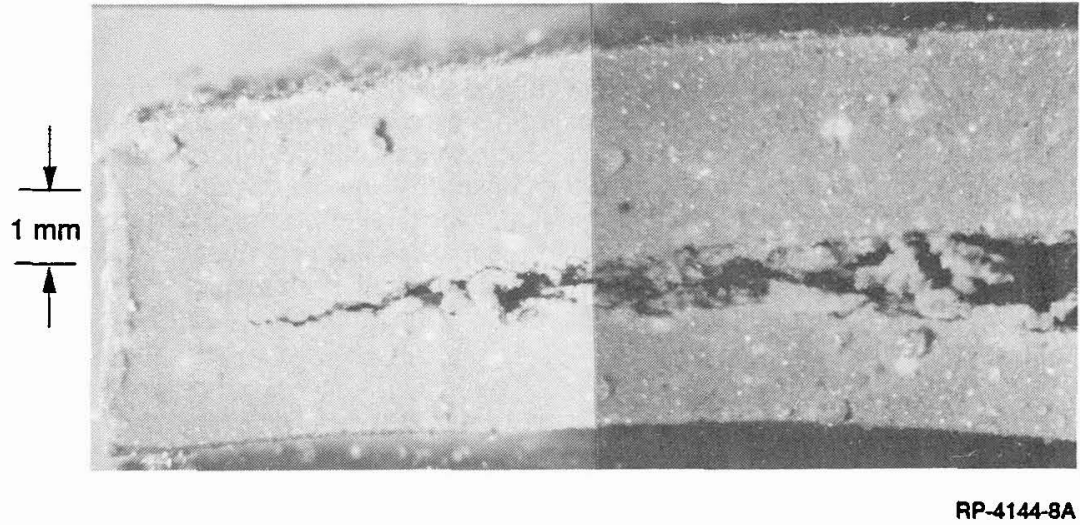

Figure 1. Optical micrograph of cross section cut through a propellant specimen (impact velocity $=145 \mathrm{~m} / \mathrm{s}$ ).

probably begins with decohesion of the explosive (HMX) grains from the matrix, although some intragranular fracture also occurs. These initial sites then link to form large, irregular, planar crack-like features normal to the direction of maximum tensile stress.

In the second type of test, a steel plate was fired at the end of a small cylinder of propellant B (as in a reverse Taylor test). The propellant cylinders were $3.06 \mathrm{~cm}$ long and $1.52 \mathrm{~cm}$ in diameter. High speed photographs were taken during the experiment in a direction normal to the direction of motion. Three tests $(19,20$, and 21$)$ were conducted at increasing velocities $(102,117$, and $156 \mathrm{~m} / \mathrm{s})$ to examine a range of damage levels. In tests 19 and 20, a few cracks were formed, but in test 21 the front (impacted) half of the specimen was almost completely fragmented. According to the high speed movies, the impacted ends of the cylinders expanded greatly during the experiment and then partially recovered. The maximum expansion of the cylinder diameters was $150 \%$ to $300 \%$ with a corresponding $50 \%$ to $75 \%$ shortening of the cylinders. The maximum deformation occurred at about one-quarter millisecond. The recovered specimens from tests 19 and 20 were $3 \%$ to $8 \%$ shorter and had a $7 \%$ to $9 \%$ larger residual diameter. This 
minor residual deformation indicates that the material is mainly viscoelastic, with only a small viscoplastic component to its response.

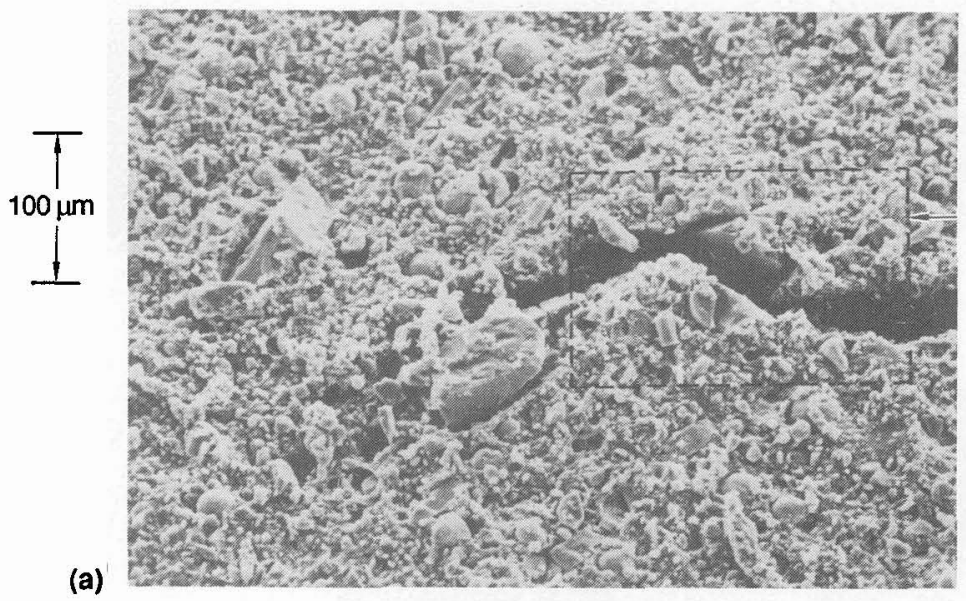

Location of

(b)

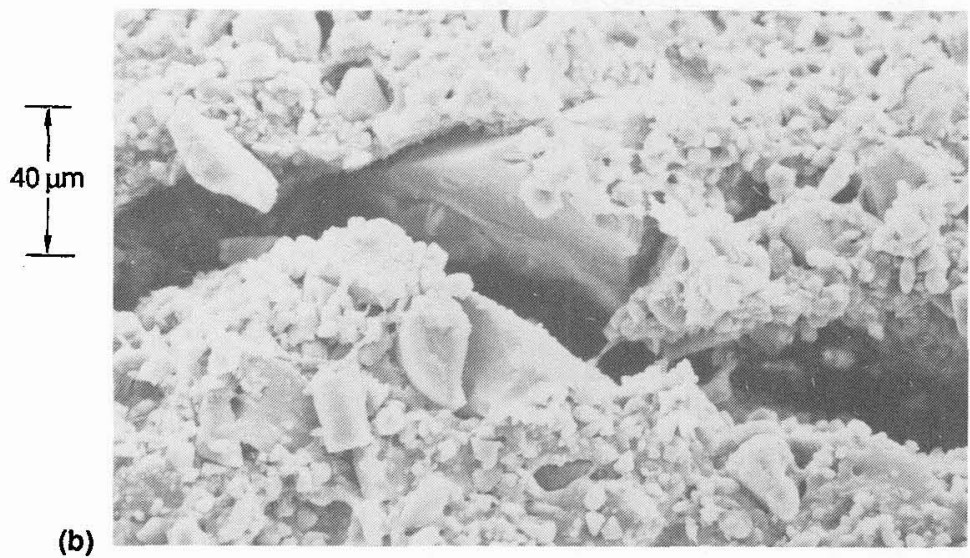

RP-4144-23

Figure 2. Scanning electron microscope views of crack from propellant in Fracture Test 9 , showing large grain debonding and fracture and one matrix ligament.

From the observations of cracking in the three specimens, we arranged the following hierarchy of tensile damage:

1. Hoop cracks (cracks with normals in the hoop direction) occur in the outer edge of the impact end, probably in response to the hoop tensions. One such crack was seen in test 19.

2. Radial cracks (normal to the radial direction), as in Figure 3, form an inner cylinder of material that is separated from the external shell. These cracks are caused by tensile stress arising from the rarefaction waves propagating from the free cylindrical surfaces toward the cylinder axis. The spalled inner cylinder is indicated by the vertical cracks in the inset of Figure 3, showing results for test 20 .

3. Continuation of the hoop cracks to form strips. These strips appeared in test 21 in which the front half of the cylinder looked like a splayed broom. 


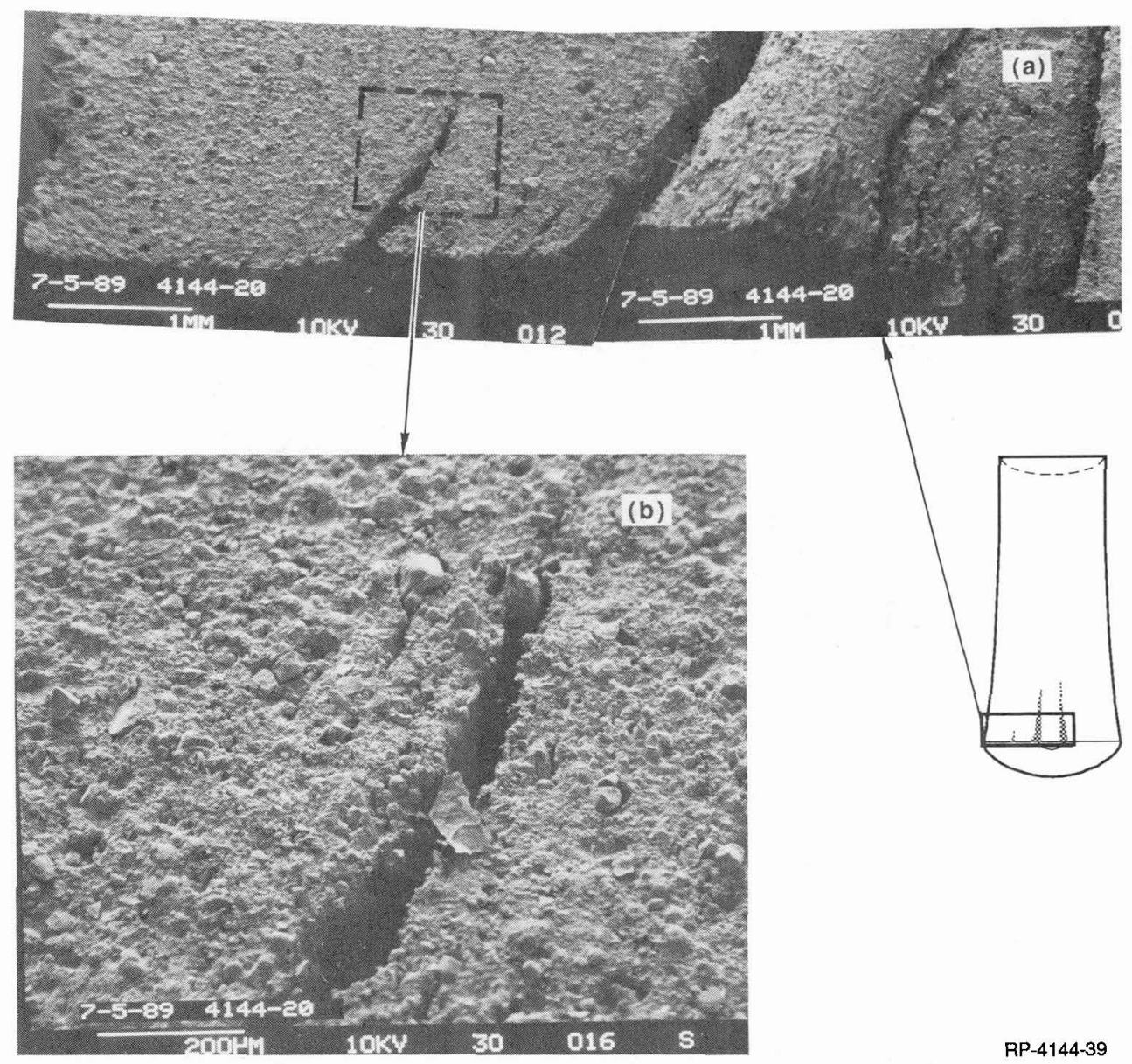

Figure 3. Scanning electron microscope views of region near impact end of cross-sectional slice through propellant specimen recovered from Shotgun Test 20.

\section{3.- Constitutive properties.}

The constitutive model we developed for the propellant consists of a nonlinear elastic pressure-volume relation, a nonlinear viscoelastic/viscoplastic model for the deviatoric stresses, and a brittle microfracture model for damage. The measured density of Propellant $B$ was $1.78 \pm 0.03 \mathrm{~g} / \mathrm{cm}^{3}$, and the longitudinal sound speed from sonic velocity measurements was $1.86 \pm 0.03 \mathrm{~km} / \mathrm{s}$. If we interpret the sound speed as the bulk sound speed (assuming that the shear stress is not able to propagate through the propellant for any significant distance), the bulk modulus is $6.2 \pm 0.3 \mathrm{GPa}$. We performed gauged gas-gun impacts to obtain a Hugoniot, but the results were conflicting and unsatisfactory. As the best representation of these impact results and the sonic velocity information, we chose the following Hugoniot:

$$
\mathrm{P}(\text { in } \mathrm{GPa})=6.2 \mu+100 \mu^{2}
$$

where $\mu=\rho / \rho_{o}-1$, the compression strain, and $\rho$ and $\rho_{o}$ are density and initial solid density.

To determine (or estimate) the deviatoric stress response (yield strength and shear modulus), we examined the meager tensile, Hopkinson bar, and impact data on three propellants or propellant simulants, as shown in Figure 4. These data show an apparently continuous increase in the yield strength and Young's 
modulus throughout the range of loading rates of interest. We fitted a viscoelastic, nonlinear unified creep-plasticity model to these data.

$$
\frac{\mathrm{d} \bar{\sigma}}{\mathrm{dt}}=3 \mathrm{G} \frac{\mathrm{d} \bar{\varepsilon}}{\mathrm{dt}}-3 \mathrm{G}\left(\frac{\bar{\sigma}}{\bar{k}}\right)^{\mathrm{n}}
$$

where $\bar{\sigma}$ and $\bar{\varepsilon}$ are the Mises stress and the imposed equivalent strain, $\mathrm{k}$ and $\mathrm{n}$ are material constants, and $\mathrm{G}$ is the shear modulus, which is also a function of the strain rate. The last term represents $3 \mathrm{G}$ times the plastic strain rate. This deviator model was added to the brittle microfracture model BFRACT [1] to represent the propellant.

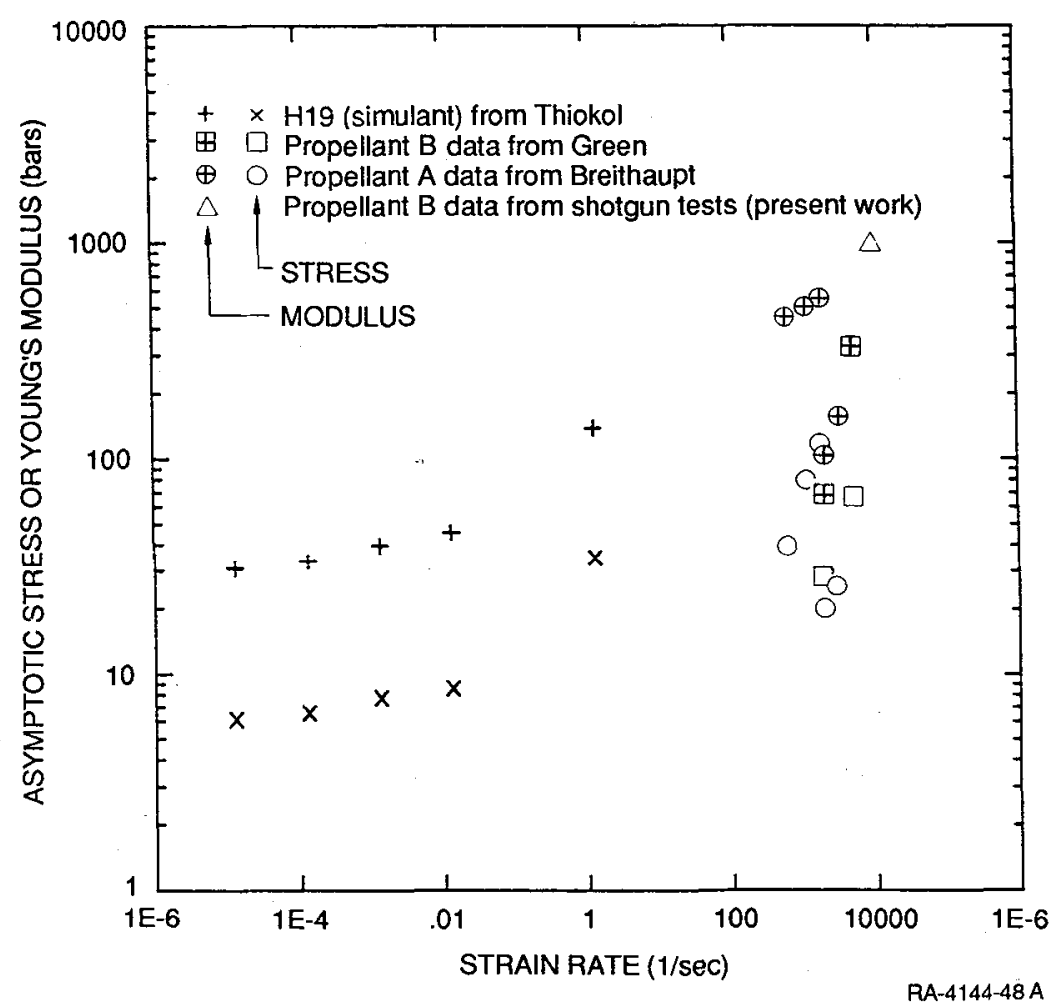

Figure 4. Young's modulus and asymptotic stress from tensile and compression tests on propellants over a range of strain rates.

\section{4.- Fracture model determination.}

For representing fracture in the propellanit, we used our nucleation-and-growth brittle microfracture model BFRACT [1]. In applying the brittle fracture model for the propellant, we used an initial size distribution of the microcracks, a nucleation rate process, a growth rate for the microcracks, and a coalescence process. As in our previous studies $[1,2]$, we used the following exponential form for the size distribution of the flaws that are nucleated during any time interval:

$$
\Delta \mathrm{N}_{\mathrm{g}}=\Delta \mathrm{N} \exp \left(-\mathrm{R} / \mathrm{R}_{\mathbf{n}}\right)
$$

where $\Delta N_{g}$ is the number of microcracks per unit volume with radii greater than $R, \Delta N$ is the total number of microcracks per unit volume in the nucleated distribution, and $R_{n}$ is a nucleation size parameter. The distribution is assumed to extend only to a maximum radius $R_{\max }$. $R_{\mathbf{n}}$ and $R_{\max }$ are material properties. 
The nucleation rate process was borrowed from previous studies on metals and plastics [1]:

$$
\frac{\mathrm{dN}}{\mathrm{dt}}=\dot{\mathrm{N}}_{\mathrm{o}}\left[\exp \left(\frac{\sigma \supseteq-\sigma_{\mathrm{no}}}{\sigma_{1}}\right)-1\right] \text { for } \sigma \text { more tensile than } \sigma_{\mathrm{no}}
$$

where $\mathrm{dN}$ is the total number per unit volume nucleated during the time interval (corresponding to $\Delta \mathrm{N}$ in Eq. 2), $N_{0}$ is a rate coefficient, $\sigma$ is the stress normal to the plane of the cracks, $\sigma_{\text {no }}$ is the nucleation threshold, and $\sigma_{1}$ is a sensitivity factor. $N_{0}, \sigma_{n 0}$, and $\sigma_{1}$ are material properties to be determined from the data.

The growth process was presumed to have the following form, obtained from the analyses of dynamic brittle fracture data:

$$
\frac{\mathrm{dR}}{\mathrm{dt}}=\mathrm{T}_{1}\left(\sigma-\sqrt{\frac{\pi}{4 \mathrm{R}}} \mathrm{K}_{\mathrm{IC}}\right) \mathrm{R} \text { for } \frac{\mathrm{dR}}{\mathrm{dt}}>0
$$

where $\mathrm{R}$ is the crack radius in plan, $\sigma$ is the stress normal to the plane of the crack, and $\mathrm{K}_{\mathrm{IC}}$ is the fracture toughness of the material. The material parameters to be determined here are $\mathrm{T}_{1}$ and $\mathrm{K}_{\mathrm{IC}}$.

When the material disintegrates, it forms fragments that are related in size and number to the microcracks present at the time of fragmentation. We recognize this relationship by prescribing a damage quantity $\tau_{\mathrm{F}}$ that varies from zero at no damage to one at full fragmentation:

$$
\tau_{\mathrm{F}}=\mathrm{T}_{\mathrm{F}} \beta \gamma^{3} \int_{0}^{\infty} \mathrm{R}^{3} \mathrm{dN}
$$

where $T_{F}$ is a numerical factor that depends on the fragment shapes, $\beta$ is the ratio of the number of fragments to the number of cracks for each radius $R$, and $\gamma$ is the ratio of the fragment radius to crack radius. The combined factor $T_{F} \beta \gamma^{3}$ was taken as $4 / 3$ in our simulations.

We derived the fracture parameters for the propellant based on the damage observations from the gas-gun impact experiments. The Propellant B fracture test results were not ideal for determining fracture model parameters. First, it was very difficult to see individual nucleated cracks. Crack nucleation was most often a decohesion of a large $\mathrm{HE}$ grain from the matrix, and cutting into the specimen often had the same effect (we cannot grind and polish the material, as we do with metals, for example, to reduce the surface roughness because the grains pull out). Only when cracks have grown to several times the largest grain size or coalesced with other cracks are they clearly visible. Second, except for tests well above the failure threshold (tests 10 and 16), the tensile damage was limited to a narrow axial region, with negligible failure evident on either side of the few visible cracks. For these reasons it is difficult to obtain statistically accurate crack size distributions as a function of axial position. Therefore, we relied on experience with other propellants and on auxiliary information to determine many of the fracture parameters.

We began the determination of the fracture parameters by estimating the size distribution of the nucleation sites from the size distribution of the HMX grains in the propellant. These had been fitted to the following functional form:

$$
\mathrm{N}_{\mathrm{g}}=1.7 \times 10^{7} \exp (-\mathrm{R} / 0.0021)
$$

where $\mathrm{N}_{\mathrm{g}}$ is the number per cubic centimeter greater than a given radius $\mathrm{R}$, in centimeters. Then we estimated all the remaining nucleation and growth parameters (listed in Table 2 ) from values obtained from previous studies on propellants.

To finalize the parameter values, we simulated the tensile tests, adjusted the parameters, and repeated the simualtions. We attempted to select a set of parameters for which the computed fracture results would meet the following criteria:

- The damage $\left(\tau_{\mathrm{F}}\right)$ values should be similar to those in Table 1. 
- The spatial extent of damage should match the observed extent (not shown).

- The numbers of cracks should approximate those in Table 1.

The resulting parameters, which allowed us to approximately meet these criteria, are listed in Table 2 . The experimentally observed damage $\left(\tau_{F}\right)$ values were closely represented by the simulations, but the numbers were not. The computational simulations show the damage spread over much of the center of the targets, although the observations indicate only narrow bands of damage; however, the simulations show narrower damage bands (17\% of the plate thickness) for the high damage cases and that trend is in general agreement with the test results. Through a sensitivity analysis for these fracture parameters, we found that all the parameters have a significant effect on the damage $\tau_{\mathrm{F}}$.

\begin{tabular}{|c|c|c|c|}
\hline Parameter & Value & Units & Descriptlon of Parameter \\
\hline$T_{1}$ & -0.015 & $1 /(\mathrm{Pa}-\mathrm{s})$ & $\begin{array}{l}\text { Crack growth coefficient, measured from growth rates } \\
\text { under several stress levels }\end{array}$ \\
\hline$K_{1 C}$ & 12.8 & $\mathrm{MPa}$ & $\begin{array}{l}\text { Dynamic fracture toughness, from size of smallest } \\
\text { growing cracks }\end{array}$ \\
\hline$R_{n}$ & 0.0021 & $\mathbf{c m}$ & $\begin{array}{l}\text { Size parameter of nucleated distribution in Eq. (3), from } \\
\text { HMX data }\end{array}$ \\
\hline$\dot{\mathrm{N}}_{0}$ & $2 ¥ 10^{17}$ & no. $/ \mathrm{m}^{3} / \mathrm{s}$ & Nucleation rate coefficient in Eq. (4) \\
\hline $\mathbf{s}_{\text {no }}$ & -80 & $\mathrm{MPa}$ & Threshold stress for nucleation \\
\hline$s_{1}$ & -20 & $\mathrm{MPa}$ & Stress sensitivity of the nucleation process \\
\hline $\mathbf{R}_{\max }$ & 0.02 & $\mathrm{~cm}$ & Maximum crack size of the nucleated distribution \\
\hline
\end{tabular}

Note: The stress sign convention is positive in compression.

\section{5.- Taylor test results.}

We attempted to quantify the deformation and fracture observations of the Taylor test results through simulations of the tests with the constitutive and fracture models. We were not able to make a good match to the deformation observations, probably because our constitutive model is largely viscoplastic, instead of viscoelastic. However, we were able to obtain similar deformed shapes, and from these computations we took the stresses that we related to the tensile damage (see section 2). In these simulations we computed tensile stresses of 120 to $150 \mathrm{MPa}$ in the locations where cracking began in tests 19 and 20 . This tensile stress is similar to that reached in spall tests 9,11 , and 17 where incipient cracking occurred. Hence, we assume that the tensile cracking process is occurring by the same mechanisms in the one-dimensional planar and axisymmetric cases. Further detailed simulations with an appropriate viscoelastic model must be undertaken to verify or refute this assumption.

\section{6.- Conclusions.}

We observed that debonding of the explosive grains from the matrix causes the tensile cracking damage. Grains generally are not cracked. Crack-like features are formed in tension although the process is a very ductile and probably a viscoelastic, viscoplastic one. Large shear strains $(>100 \%)$ appear not to cause fracture, but even small tensile strains lead to cracking. Essentially the same tensile cracking process appears to control, both in planar geometries in which the stress state is uniaxial tension and in twodimensional geometries in which the stress state may be dominated by high shear flows. The material 
appears to be highly viscoelastic (large shear strains are largely recoverable) but to have some viscoplastic response also. The nucleation-and-growth brittle microfracture model BFRACT was able to represent the tensile damage in plate impact experiments fairly satisfactorily. Similar fracture simulations could not be made for the cylinder impacts because we lacked a suitable viscoelastic constitutive model.

\section{References}

/1/ SEAMAN, L, J. Appl. Mech. 107 (1985) 593.

/2/ CURRAN, D R, SEAMAN, L, and SHOCKEY, D A, Phys. Repts. 147 (1987) 253 